\title{
Critical Care and Emergency Medicine
}

\section{Electrocardiographic Brugada Pattern Unmasked by Febrile Illness}

\author{
Antonio Villa ${ }^{1 *}$, Alfredo Corticelli ${ }^{2}$, Luisa Chiappa ${ }^{2}$ and Antonella Savinelli ${ }^{1}$ \\ ${ }^{1}$ Department of Emergency, Ospedale di Desio, Italy \\ ${ }^{2}$ Department of Cardiology, Ospedale di Desio, Italy
}

*Corresponding author: Antonio Villa, Department of Emergency, Ospedale di Desio, ASST Monza, Via Fiuggi, 56, Milano, 20159, Italy

\begin{abstract}
Brugada syndrome is associated with a high risk of sudden cardiac death and some authors suggested the possibility that a febrile state may unmask the Brugada syndrome.

We present a case of fever-induced type I electrocardiographic Brugada pattern.

This is well known among the cardiologists, but it is necessary to introduce this clinical entity to other specialists, especially among internists and physicians of the emergency.
\end{abstract}

\section{Keywords}

Brugada, Electrocardiogram, Fever

\section{Introduction}

Brugada syndrome, first described in 1992 as a new clinical entity by Pedro and Josep Brugada [1], is an autosomal dominant disease associated with a high risk of sudden cardiac death in healthy young people [2]. In 2000, some authors suggested the possibility that a febrile state may unmask the Brugada syndrome and in the years thereafter many more examples have been reported [3-12]. This is well known among the cardiologists, but it is necessary to introduce this phenomenon to other specialists, especially among internists and physicians of the emergency.

We present a case of fever-induced type I electrocardiographic (ECG) Brugada pattern.

\section{Case Report}

A 39-year-old male came to our Emergency Depart- ment with fever, cough and flu symptoms. He had no family history of sudden death, nor experienced any episode of syncope. On admission his body temperature was $38.8^{\circ}$. The cardiovascular and respiratory examinations were normal, the blood sample and the chest $x$-ray were normal. Electrocardiogram showed ST elevation in lead V1-V2 with right bundle branch block typical of Brugada pattern (Figure 1).

He was admitted in Cardiology ward and there was no evidence of structural heart disease as shown by a normal echocardiogram. The electrophysiological study was normal.

After therapy with paracetamol he showed clinical improvement and was no more febrile. An electrocardiogram with normal temperature demonstrated reversibility of the ECG Brugada pattern (Figure 2).

\section{Discussion}

Brugada syndrome is characterized by a typical pattern of electrocardiogram with right bundle branch block and a coved-type ST-segment elevation $\geq 2$ $\mathrm{mm}$ in the right precordial leads ("type I" ECG Brugada pattern) $[2,13]$. Types II and III, which are not truly diagnostic of Brugada pattern, are characterized by a "saddle-back" ST-segment elevation, that is $\geq 2 \mathrm{~mm}$ in type II and < $1 \mathrm{~mm}$ in type III $[2,13]$. Displacement of the right precordial leads electrodes one or two intercostal spaces above their normal positions may disclose the diagnostic pattern when conventional leads, recorded at the fourth intercostal space, are non-diagnostic or even normal. High right precordial

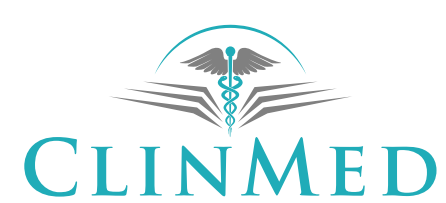

INTERNATIONAL LIBRARY
Citation: Villa A, Corticelli A, Chiappa L, Savinelli A (2019) Electrocardiographic Brugada Pattern Unmasked by Febrile Illness. Int J Crit Care Emerg Med 5:093. doi.org/10.23937/2474-3674/1510093 Accepted: December 02, 2019: Published: December 04, 2019

Copyright: (C) 2019 Villa A, et al. This is an open-access article distributed under the terms of the Creative Commons Attribution License, which permits unrestricted use, distribution, and reproduction in any medium, provided the original author and source are credited. 


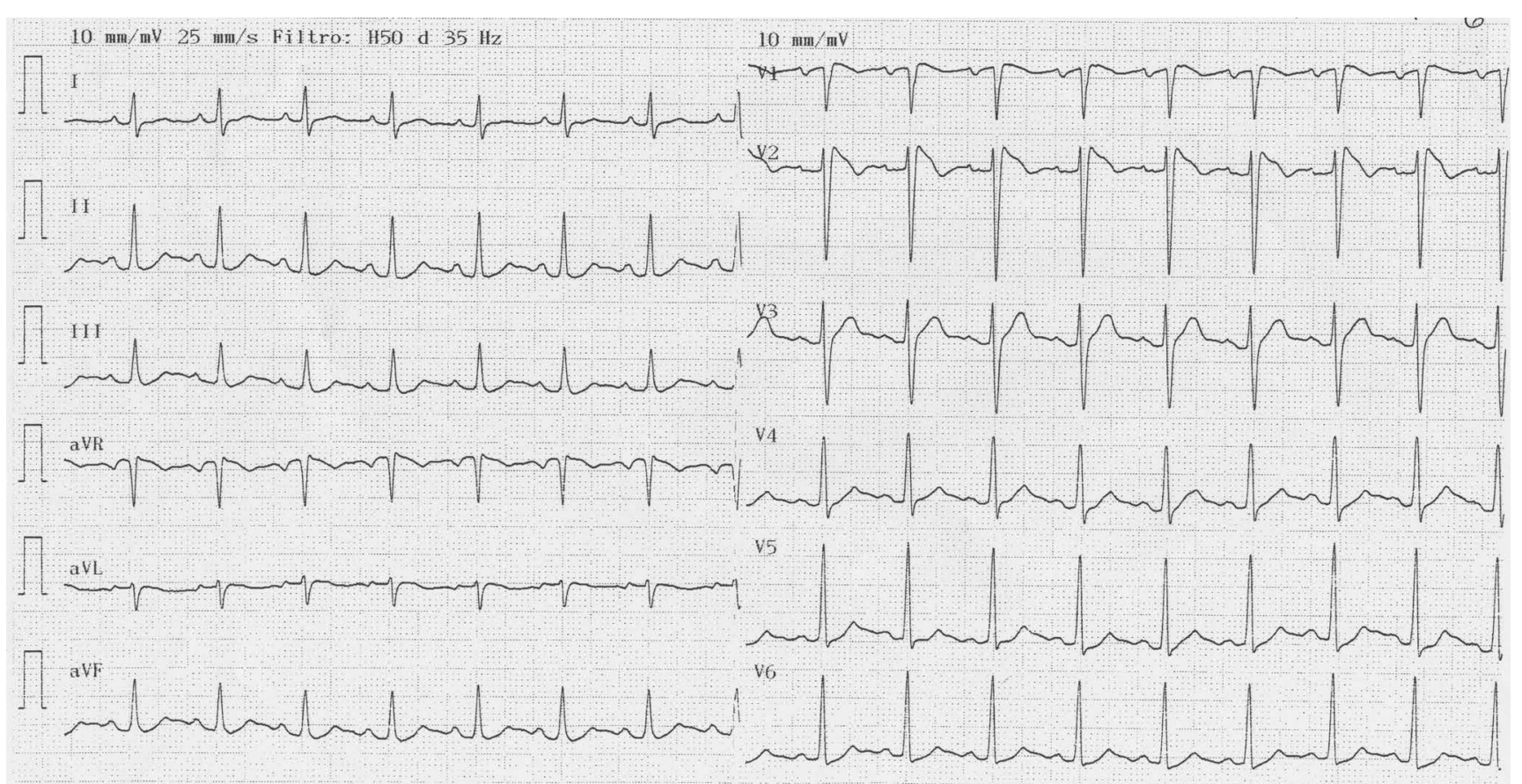

Figure 1: On arrival electrocardiogram showed right bundle branch block and a "coved-type" ST elevation in lead V1-V2 (type I ECG Brugada pattern).

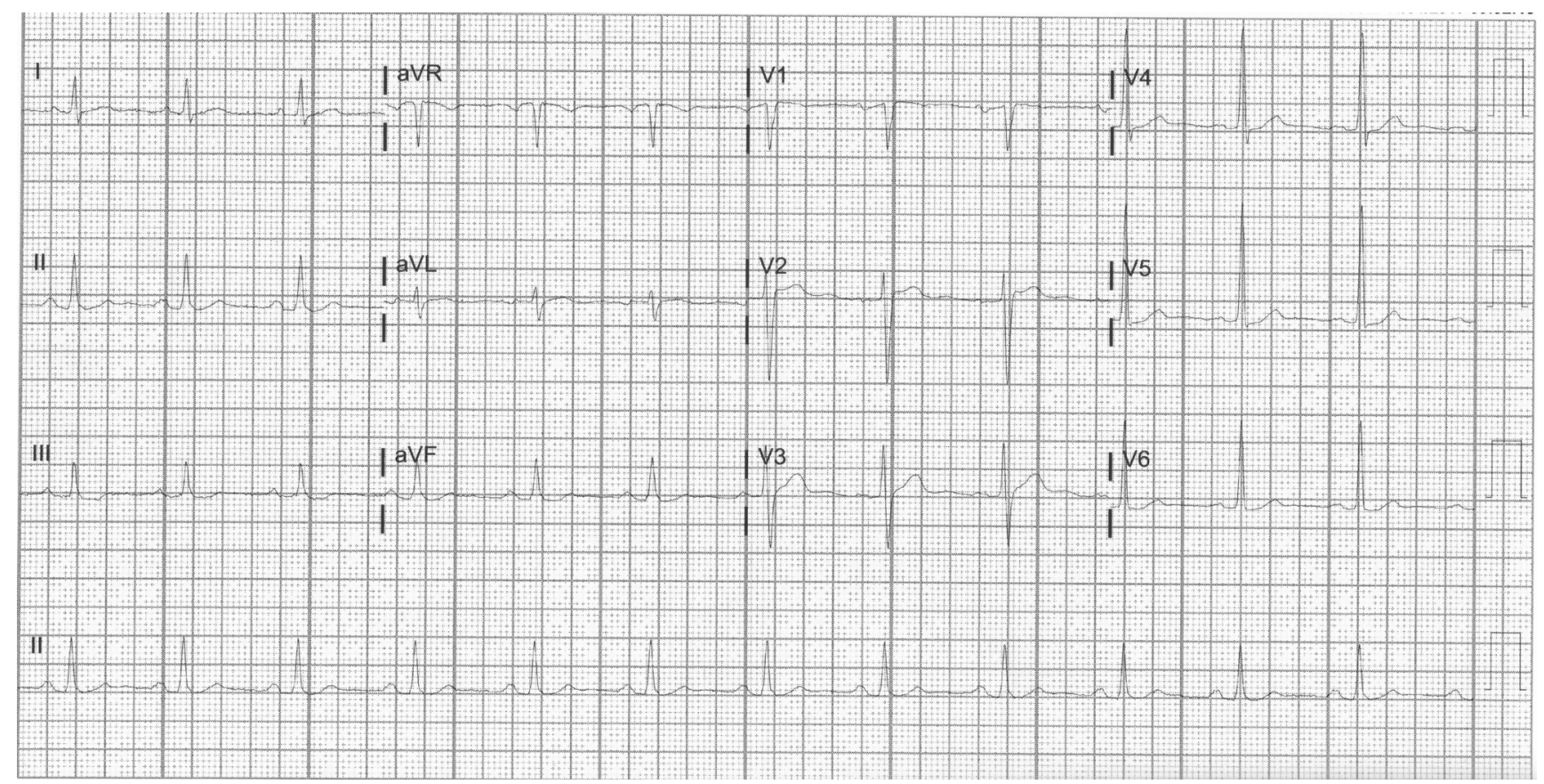

Figure 2: Reversibility of the ECG Brugada pattern after normalization of temperature.

leads should be recorded whenever standard V1-V3 leads raise the suspicion of Brugada pattern $[2,14]$.

Brugada syndrome should only be established in presence of a type I ECG pattern associated with at least one of the following clinical criteria: Documented ventricular fibrillation or polymorphic ventricular tachycardia, family history of sudden cardiac death at $<45$ years of age or type I ECG pattern in other family members, inducible ventricular arrhythmias during electrophysiological study, syncope or nocturnal agonal respiration $[2,13]$.
The term "Brugada syndrome" should be restricted to patients who have diagnostic ECG changes, as well as a history of symptoms. Asymptomatic subjects should be categorized as having a ECG Brugada "pattern" or "sign" [2].

This disease shows an extreme variability in clinical presentation, due to its dynamic nature; there are marked day-to day changes in ECG pattern and electrocardiogram can show type I, II, and III patterns in a single patient at different times or even be temporarily normal [13]. 
ECG changes are dynamic, often hidden, and may reveal themselves in the presence of triggers like fever, intoxication (alcohol, cocaine, cannabis), vagal stimulation, electrolyte imbalance, anesthetics (propofol, bupivacaine), psychotropic agents (amitriptyline, lithium), and sodium channel blockers $[11,15,16]$.

Fever-induced Brugada signs is becoming a well known entity. Adler and coll. [17] showed that type I ECG Brugada pattern was 20 times more common in the febrile patients than in the afebrile group.

This syndrome is included among the so called channel opathies and some studies have noted that cardiac sodium channel mutations can result in temperature gated channel whose potential for arrhythmogenicity increases with higher temperature $[8,18]$.

An association between fever and sudden death (due to arrhythmias), beyond the Brugada syndrome, has also been recently reported in a patient with a congenital long QT syndrome; during a febrile episode he showed an arrhythmogenic syncope with appearance of "torsade de pointes" secondary to further lengthening of the QT period [19].

So therefore, often prompt and aggressive control of fever is crucial in preventing malignant arrhythmias [20].

\section{Conclusions}

There are not clear-cut guidelines on the use of routine electrocardiogram in patient admitted with non-cardiac illnesses, but an electrocardiogram done as a part of routine workup in the Emergency Department could contribute to increase the evidence of Brugada pattern, especially in febrile patients [11].

This phenomenon is well known among the cardiologists, but it necessary to introduce this clinical entity to other specialists, especially among internists and physicians of the emergency.

\section{Contributions}

AC, LC and AS were responsible for the clinical management of the treated patient and for the manuscript reviewing.

AV was responsible for the preparation of the manuscript.

\section{Conflict of Interests}

The authors declare no potential conflict of interests.

\section{References}

1. Brugada P, Brugada J (1992) Right bundle branch block, persistent ST segment elevation and sudden cardiac death: A distinct clinical and electrocardiographic syndrome. A multicenter report. J Am Coll Cardiol 20: 1391-1396.

2. Antzelevitch $C$, Brugada $P$, Borggrefe M, Brugada J, Brugada R, et al. (2005) Brugada syndrome: Report of the second consensus conference: Endorsed by the heart rhythm society and the european heart rhythm association. Circulation 111: 659-670.

3. González Rebollo JM, Hernández Madrid A, García A, García de Castro A, Mejías A, et al. (2000) Recurrent ventricular fibrillation during a febrile illness in a patient with the brugada syndrome. Rev Esp Cardiol 53: 755-757.

4. Saura D, García-Alberola A, Carrillo P, Pascual D, Martínez-Sánchez J, et al. (2002) Brugada-like electrocardiographic pattern induced by fever. Pacing Clin Electrophysiol 25: 856-859.

5. Morita H, Nagase S, Kusano K, Ohe T (2002) Spontaneous $T$ wave alternans and premature ventricular contractions during febrile illness in a patient with Brugada syndrome. $J$ Cardiovasc Electrophysiol 13: 816-818.

6. Porres JM, Brugada J, Urbistondo V, García F, Reviejo K, et al. (2002) Fever unmasking the Brugada syndrome. Pacing Clin Electrophysiol 25: 1646-1648.

7. Kum LC, Fung JW, Sanderson JE (2002) Brugada syndrome unmasked by febrile illness. Pacing Clin Electrophysiol 25: 1660-1661.

8. Keller DI, Rougier JS, Kucera JP, Benammar N, Fressart V, et al. (2005) Brugada syndrome and fever: genetic and molecular characterization of patients carrying SCN5A mutations. Cardiovasc Res 67: 510-519.

9. Amin AS, Meregalli PG, Bardai A, Wilde AA, Tan HL (2008) Fever increases the risk for cardiac arrest in the Brugada syndrome. Ann Intern Med 149: 216-218.

10. Erdogan O, Hunuk B (2013) Frequency of Brugada type ECG pattern in male subjects with fever. Int J Cardiol 165: 562-563.

11. Manohar S, Dahal BR, Gitler B (2015) Fever-induced Brugada syndrome. J Investing Med High Impact Case Rep 3.

12. Marta Madeira, Francisca Caetano, Rui Providencia, Ines Almeida, Joana Trigo, et al. (2015) Fever-induced type 1 Brugada pattern. Rev Port Cardiol 34: 287.

13. B Begoňa, J Brugada, R Brugada, P Brugada (2009) Brugada syndrome. Rev Esp Cardiol 62: 1297-1315.

14. Oreto G, Corrado D, Delise P, Fedele F, Gaita F, et al. (2010) Doubts of the cardiologist regarding an electrocardiogram presenting QRS V1-V2 complexes with positive terminal wave and ST segment elevation. Consensus Conference promoted by the Italian Cardiology Society. G Ital Cardiol 11: 3S-22S.

15. Francis J, Antzelevitch C (2005) Brugada syndrome. Int J Cardiol 101: 173-178.

16. Postema PG, Wolpert C, Amin AS, Probst V, Borggrefe M, et al. (2009) Drugs and Brugada syndrome patients: Review of the literature, recommendations, and an up-to-date website (www.brugadadrugs.org). Heart Rhythm 6: 1335-1341.

17. Adler A, Topaz G, Heller K, David Zeltser, Tami Ohayon, et al. (2013) Fever-induced Brugada pattern: How common is it and what does it mean? Heart Rhythm 10: 1375-1382.

18. Dumaine $R$, Towbin JA, Brugada $P$, Vatta $M$, Nesterenko DV, et al. (1999) lonic mechanisms responsible for the electrocardiographic phenotype of the Brugada syndrome are temperature dependent. Circ Res 85: 803-809.

19. Rodríguez-Artuza C, Osorio J, Madueňo F, Payares A (2016) Fever and sudden death, a reality: Illustrative case report. Medwave 16: e6613.

20. Junttila MJ, Gonzalez M, Lizotte E, Benito B, Vernooy K, et al. (2008) Induced Brugada-type electrocardiogram, a sign for imminent malignant arrhythmias. Circulation 117: 18901893. 